\title{
Aplicación de la terapia cognitivo-conductual con componentes de clarificación de valores y activación conductual en un caso de trastorno de estrés postraumático
}

\author{
Alba Hernández Gómez \\ Universidad Autónoma de Madrid
}

RESUMEN

El objetivo del presente trabajo es la formulación clínica del caso, la descripción del tratamiento $y$, la presentación de los resultados del caso clínico de una mujer de 53 años con un diagnóstico de trastorno de estrés postraumático (TEPT) de inicio demorado junto con síntomas depresivos, agorafóbicos y ansiedad social. En la intervención se aplicaron técnicas de la terapia cognitivo conductual (TCC) con el componente de clarificación de valores de la terapia de aceptación y compromiso (ACT) y la activación conductual (AC). En los resultados se observó una mejora en la sintomatología y en el funcionamiento de la paciente en las diferentes áreas vitales. Por último, se discute el potencial de la combinación de técnicas de diferentes enfoques terapéuticos para mejorar el abordaje de esta problemática

Palabras clave: trastorno de estrés postraumático; terapia cognitivo-conductual; clarificación de valores; terapia de aceptación y compromiso; activación conductual.

\section{ABSTRACT}

The aim of this article is the clinical case formulation, to describe the treatment and to present the results of the clinical case of a 53 years old woman with post-traumatic stress disorder (PTSD) start delayed along with depressive, agoraphobic symptoms and social anxiety. In the intervention we applied techniques from cognitive behavioral therapy (CCB) with the values clarification component from acceptance and commitment therapy (ACT) and behavioral activation (BA). Regarding the results, an improvement of the symptoms and working of the patient in the different vital areas was showed. Finally, we discuss the implications of the combination of techniques from different therapeutic approaches in order to improve the treatment of this disorder.

Keywords: post-traumatic stress disorder; cognitive-behavioral therapy; values clarification; acceptance and commitment therapy; behavioral activation. 


\section{Introducción}

La exposición a eventos traumáticos o profundamente estresantes durante la vida es casi inevitable (Perrin et al., 2014). En el ser humano, estos sucesos producen una reacción normal caracterizada por sentimientos de terror, vulnerabilidad e indefensión. Sin embargo, en ocasiones, la persona carece de recursos suficientes para afrontar la situación, desencadenándose el Trastorno de Estrés Postraumático (TEPT) (Sosa \& Capafóns, 2010).

Según el DSM-5 (American Psychiatric Association, 2013) los síntomas nucleares de este cuadro clínico son los recuerdos recurrentes, involuntarios e intrusivos junto con sueños angustiosos sobre el acontecimiento. También se experimentan reacciones disociativas, malestar psicológico y reacciones fisiológicas intensas al exponerse a factores que simbolizan al suceso. Incluso, los individuos tienden a manifestar una evitación persistente de estímulos asociados al trauma.

Con respecto a la prevalencia de esta patología, en EE. UU., a través de un estudio Kessler, Sonnega, Bromet, Hughes y Nelson (1995) encontraron una prevalencia de $7,8 \%$ entre los respondientes (un 5\% de hombres y un 10,4\% de mujeres). En España se estima que la prevalencia es de un $8,47 \%$ en el grupo psiquiátrico y un 2,22\% en la población general (Orengo, Rodríguez, Lahera, \& Ramírez, 2001).

Los sucesos desencadenantes del trastorno pueden ser causados intencionalmente por el ser humano (violaciones, agresión sexual...) o, ser accidentales (desastres naturales, accidentes...). Los investigadores apuntan a que el riesgo de TEPT asociado con un abuso sexual es mayor que el vinculado con otras categorías de traumas (Perrin et al., 2014). De este modo, las experiencias sexuales involutivamente inapropiadas en la infancia pueden desencadenar esta patología (Ayala \& Ochotorena, 2004; Bados, 2005; Sarasua, Zubizarreta, Corral, \& Echeburúa, 2013).

De lo que no hay lugar a dudas es que el abuso sexual infantil (ASI) deja huella en la vida de las víctimas pudiendo desencadenar, junto con el TEPT, otras alteraciones (p. ej., Cannon, Bonomi, Anderson, Rivara, \& Thompson, 2010; DiLillo, 2001; Pereda, 2010; Pereda, GallardoPujol, \& Jiménez, 2011).

Con el propósito de dar cuenta del desarrollo y mantenimiento del TEPT se han propuesto diferentes teorías explicativas, desde las más conductuales a otras que incorporan aspectos de carácter cognitivo. Entre ellas cabe destacar la teoría bifactorial de Mowrer (1960), la teoría del procesamiento emocional (Foa, Hembree, \& Rothbaum, 2007; Foa \& Kozak, 1986; Foa \& Rothbaum, 1998), la teoría del procesamiento de la información (Resick, Monson, \& Chard, 2014; Resick, Nishith, Weaver, Astin, \& Feuer, 2002; Resick \& Schnicke, 1992), la teoría de la representación dual (Brewin, 1989; Brewin, Dalgleish, \& Joseph, 1996) y, la teoría cognitiva (Ehlers \& Clark, 2000).

Cuando se trata de tratamientos para este trastorno, las intervenciones cognitivo- conductuales parecen ser las que cuentan con mayor respaldo empírico (Foa \& Meadows, 1997; Van Etten \& Taylor, 1998). Concretamente, la terapia de exposición se ha demostrado eficaz en el TEPT (Foa, Gillihan, \& Bryant, 2013; McLean \& Foa, 2011; Rothbaum, Meadows, Re- 
sick, \& Foy, 2003), llegando a ser considerada el tratamiento de elección (Foa et al., 2007; Foa \& Rothbaum, 1998). Asimismo, algunos autores han señalado la eficacia de la reestructuración cognitiva (Mueser et al., 2015), las técnicas de manejo de la ansiedad (Báguena, 2001) y, el entrenamiento en inoculación de estrés (Foa $\&$ Meadows, 1997). Sin embargo, pese a la demostrada eficacia de la TCC en el tratamiento del TEPT se han identificado ciertas limitaciones en sus procedimientos. En este sentido, las técnicas de exposición resultan eficaces para el abordaje de la sintomatología de hiperactivación. No obstante, tienen menos impacto en la sintomatología evitativa. De forma similar, los pacientes encuentran dificultades a la hora de adherirse al tratamiento $y$, frecuentemente abandonan (Mulick, Landes, \& Kanter, 2011; Orsillo \& Batten, 2005; Orsillo, Roemer, Lerner, \& Tull, 2004).

En los últimos años, inspiradas en el conductismo radical, se ha producido el auge de la "Tercera ola de generaciones" (Valero \& Ferro, 2015 , p. 21). Entre las que se encuentran la terapia de aceptación y compromiso (ACT) (Hayes \& Smith, 2005; Hayes, Strosahl, \& Wilson, 2015) y, la terapia de activación conductual (AC) (Barraca \& Pérez-Álvarez, 2015), las cuales suponen un cambio en el foco terapéutico.

Por un lado, en la ACT, la intervención se aleja del modelo médico característico de la TCC. De esta forma, no se dirige únicamente a la reducción o eliminación de los síntomas sino también a que la persona pueda distanciarse de ellos y reorientar el sentido de su vida (Mulick et al., 2011; Pérez-Álvarez, 2012). A su vez ofrece una alternativa funcional a la gran variedad de diagnósticos de los sistemas CIE y DSM en la denominación de trastorno de evitación experiencial (TEE) (Ferro, 2000; Hayes, Strosahl, \& Wilson, 1999; Hayes, Wilson, Gifford, Follette, \& Strosahl, 1996; Luciano, Gutiérrez, \& Rodríguez, 2005) y, propone un modelo transdiagnóstico basado en la flexibilidad psicológica (Pérez-Álvarez, 2012). Esta habilidad implica no evitar, controlar o cambiar los eventos privados internos o la propia situación (Ferro, 2000).

Por su parte, desde la filosofía de la AC se entiende la depresión en términos contextuales (Bianchi \& Muñoz, 2014), contribuyendo a la desmedicalización y ayudando a las personas deprimidas a reengancharse a sus vidas (Pérez-Álvarez, 2007). La aplicación de la AC al TEPT se concibe como una forma sutil de exposición. No obstante, a diferencia de la clásica terapia comportamental, el propósito explícito no es la extinción sino el despliegue de una actividad valiosa (Higuera, 2006; Mulick et al., 2011). Por lo que se refiere a los valores entendemos aquellas cualidades elegidas por los individuos para orientar su vida. Por otro lado, frente a la terapia internalista de corte cognitivo, desde esta perspectiva no interesa tanto el contenido de las cogniciones como su función (Barraca \& Pérez-Álvarez, 2015).

Por último, tanto la ACT como la AC han sido aplicadas para el tratamiento del TEPT y otras patologías como la depresión (p. ej., Barraca, 2010; Mulick \& Naugle, 2010; Twohig, 2009).

En la revisión de la literatura se encuentran intervenciones en las que se han integrado procedimientos de la TCC con componentes de las terapias contextuales. En este sentido, esta 
combinación de procedimientos se ha aplicado en el trastorno de personalidad límite (TLP) (Becker \& Zayfert, 2001), en experiencias traumáticas (Follette, Palm, \& Rasmussen, 2004), en ansiedad social (Grumet \& Fitzpatrick, 2016) y, en ansiedad generalizada (Orsillo, Roemer, \& Barlow, 2003).

Sin embargo, pese al avance en la investigación acerca de los tratamientos para el TEPT, hasta nuestro conocimiento, todavía no se han diseñado intervenciones en las que se combinen la TCC con el componente específico de clarificación de valores y la AC. Esta combinación de procedimientos podría representar una manera más funcional e idiosincrática de abordar la sintomatología de este cuadro clínico. En particular, esta composición podría contribuir a reducir a la vez que cambiar la relación que el paciente mantiene con sus síntomas. Inclusive, estos desarrollos podrían atajar las limitaciones de las clásicas intervenciones cognitivo conductuales, refinando los tratamientos $y$, reduciendo la cronicidad y sufrimiento que conlleva este trastorno (Orsillo \& Batten, 2005).

A continuación, se expone el caso de una paciente diagnosticada con TEPT de inicio demorado, junto con síntomas depresivos, agorafóbicos y de ansiedad social secundarios a esta patología. La paciente fue sometida a una intervención en la que se aplicaron técnicas de la TCC con el componente específico de clarificación de valores de la ACT y la AC. El objetivo del presente estudio es determinar la eficacia del tratamiento en la disminución de la sintomatología del TEPT y, de los síntomas secundarios depresivos, agorafóbicos y de ansiedad social.

\section{Identificación del paciente y motivo de consulta}

M es una mujer de 53 años de edad, nacida en un pequeño pueblo de Alicante, con nivel económico medio. No trabaja ni tiene estudios. En el presente, la paciente reside en una ciudad de Madrid. Además, está casada y tiene una hija de 28 años. Es la menor de dos hermanos, el otro es varón.

Acude a consulta por voluntad propia. Según refiere, últimamente se encuentra más decaída de lo habitual, triste, sin ganas de hacer nada, muy irritable y con frecuentes conductas de enfado. Más aún, ella presenta cefaleas, dolores de espalda y espasmos musculares en el estómago. Nos relata que sufrió abusos sexuales en su infancia cuando tenía 9 años por parte de un pariente cercano. En el momento actual, manifiesta recuerdos intrusivos consistentes en imágenes acerca del suceso. Por otro lado, ella denota tener dificultades en las relaciones interpersonales, ser profundamente desconfiada y no salir más tarde de las diez de la noche. Habitualmente, necesita salir a la calle acompañada.

Actualmente, $\mathrm{M}$ ha tomado la decisión de acudir a terapia porque piensa que necesita contar lo ocurrido y reorientar el sentido de su vida.

Los abusos comenzaron cuando M tenía 9 años de edad. Estos consistieron en tocamientos. Ella no contó a nadie nada sobre lo ocurrido. No obstante, sus progenitores se enteraron debido a la revelación de los padres de una vecina de su edad, de quien el agresor había intentado abusar. Pronto, el rumor del abuso de $M$ se difundió por todo el pueblo. Más 
adelante, la paciente confiesa haber intentado repetir el acontecimiento con otro adulto. Sin embargo, el hombre rechazó su petición.

$M$ relata que siempre fue una niña feliz, vital y extrovertida. No obstante, desde el ASI su personalidad cambió. Desde entonces, comenzó a ser tímida y desconfiada con las demás personas. "Me convertí en una niña huraña y retraída. No me gustaba estar con nadie. Empecé a huir de la gente. No hablaba nada". Refiere que comenzó a presentar dificultades para concentrarse y estudiar, por ende, empezó a no querer acudir al colegio. No llegó a sacarse el graduado escolar. Los dolores de tripa también empezaron a ser habituales. Por la mañana, $M$ rehusaba de levantarse de la cama. Cuenta cómo su madre enfadada acudía a despertarla con una piña en la mano prendida con fuego o, con un cuchillo para matar a los cerdos.

Respecto a la dinámica familiar, alega que sus padres eran muy fríos, no mostraban afecto $y$, las discusiones eran frecuentes en el hogar. Varios días a la semana, su padre se emborrachaba. Entonces, él llegaba a casa a la madrugada y golpeaba a su madre. En estas circunstancias, a los 16 años, M no deseaba continuar viviendo en su pueblo. Por consiguiente, aprovechando que su hermano se marchaba a la capital se fue con él. En Madrid, la paciente conoció a su marido y a los 23 años de edad contrajo matrimonio.

Durante un tiempo, $M$ olvidó el episodio traumático. Pero, volvió a recordar el suceso cuando su hija tuvo la misma edad en la que ella sufrió el abuso. A pesar de ello, nunca contó a nadie lo acontecido. "Agaché la cabeza, callé y guardé en mi memoria". M alude que estu- vo mucho tiempo sin acudir a su pueblo. Años después, regresó experimentando recuerdos e imágenes intrusas del episodio traumático cuando pasaba por determinados lugares.

La paciente expone que, en cierta medida, este episodio ha podido marcar su vida. Así, desde hace un tiempo, ha comenzado a tener recuerdos e imágenes intrusivas del ASI. Éstas aparecen ante distintas situaciones: cuando acude a su pueblo, lee en el periódico o ve en la televisión noticias acerca de episodios de abuso, pasea de noche por la calle, está sola o acude a terapia... Las imágenes le desencadenan temor y ansiedad. También expresa que siente culpa y vergüenza. Lo que más vergüenza le genera es el hecho de que ella intentó tener tocamientos con otro adulto. Es más, indica tener remordimientos por haber consentido que abusaran de ella y no habérselo contado a sus padres.

Por otro lado, M se define como una persona apática, con grandes dificultades para disfrutar de los acontecimientos de la vida. En la actualidad, la paciente apenas sale de casa y ha abandonado sus actividades y reuniones sociales. Además, declara que presenta inestabilidad emocional, lo que le llevó a acudir al médico de cabecera, quien le recetó Orfidal. No obstante, la paciente no llegó a tomar la medicación y recurrió a productos naturales como la jalea real.

En relación con sus relaciones sociales, aunque pasa la mayor parte del tiempo sola, mantiene una buena relación con su familia y tiene varios grupos de amigas. No obstante, la paciente se muestra preocupada por sus dificultades en este ámbito. De este modo, presenta 
ansiedad cuando se trata de enviar y responder a mensajes de WhatsApp o quedar con sus amigas. También explica que suele ir acompañada de su marido, no realizando actividades en solitario.

Las expectativas que $\mathrm{M}$ tiene sobre el proceso terapéutico y su problema es que cree que la terapia puede ayudarle a sentirse mejor y a recuperar el tiempo perdido. Así, la paciente muestra una alta motivación para el tratamiento, proporciona siempre la información solicitada y cumple con las tareas semanales. A pesar de sus niveles de ansiedad y dificultades sociales, ha logrado conservar su matrimonio y criar a su hija. Encima, su familia la apoya en el proceso terapéutico. Con anterioridad, $\mathrm{M}$ ha participado en cursos de inteligencia emocional y autoestima.

\section{Estrategias de evaluación}

La evaluación inicial del problema consistió en una entrevista abierta con el fin de recabar la información necesaria para el establecimiento del análisis funcional. También se emplearon una serie de autoinformes y autorregistros.

En primer lugar, con la intención de evaluar la sintomatología del TEPT y el grado de inadaptación global de la paciente, se administró la Escala de Gravedad de Síntomas del TEPT (Echeburúa, de Corral, Amor, Zubizarreta, \& Sarasua, 1997; Echeburúa, de Corral, Zubizarreta, \& Sarasua, 1995) y, la Escala de Inadaptación (Echeburúa, de Corral, \& Fernández-Montalvo, 2000). En el primer instrumento, la paciente obtuvo una puntuación de 27 sobre un máximo de 51 , con un punto de corte de 15 . Mientras que, en la segunda escala, su puntuación fue de 27 sobre 36 , con un punto de corte de 12.

En segundo lugar, su estado de ánimo se evaluó semanalmente mediante la administración del inventario de Depresión de BeckII (BDI-II) (Beck, Steer, \& Brown, 2011). Obtuvo una puntuación de 32 entre 0 y 63 , lo que correspondía a una depresión grave.

En tercer lugar, para evaluar su nivel de ansiedad se administró el Cuestionario de Ansiedad Estado-Rasgo (STAI) (Spielberger, Gorsuch, \& Lushene, 2011). La paciente se situó en el percentil 90 para Ansiedad-Rasgo y 95 para Ansiedad-Estado.

En cuarto lugar, la evaluación de la autoestima se realizó a través de la cumplimentación de la Escala de Autoestima de Rosenberg (1973), la cual presenta propiedades psicométricas satisfactorias en la población española (Vázquez, Jiménez, \& Vázquez-Morejón, 2004). La paciente obtuvo una puntuación de 28 , a partir de la cual se valoró que su nivel de autoestima era medio.

En quinto lugar, se administró la Escala de Actitudes Disfuncionales (DAS) adaptada al español por Bas y Andrés (1994) para medir las cogniciones latentes que supuestamente juegan un papel causal en la depresión (Sanz \& Vázquez, 1994). El perfil de Actitudes Disfuncionales en el pre-tratamiento se presenta en la Figura 1.

Como se observa en la Figura 1, el miedo a ser criticada y la necesidad de ser aprobada (Factor 1), la idea de que necesita a alguien que la ame y que si no la gente a la que quiere la rechaza porque se está equivocando en algo (Factor 2), cierto perfeccionismo (Factor 4), 


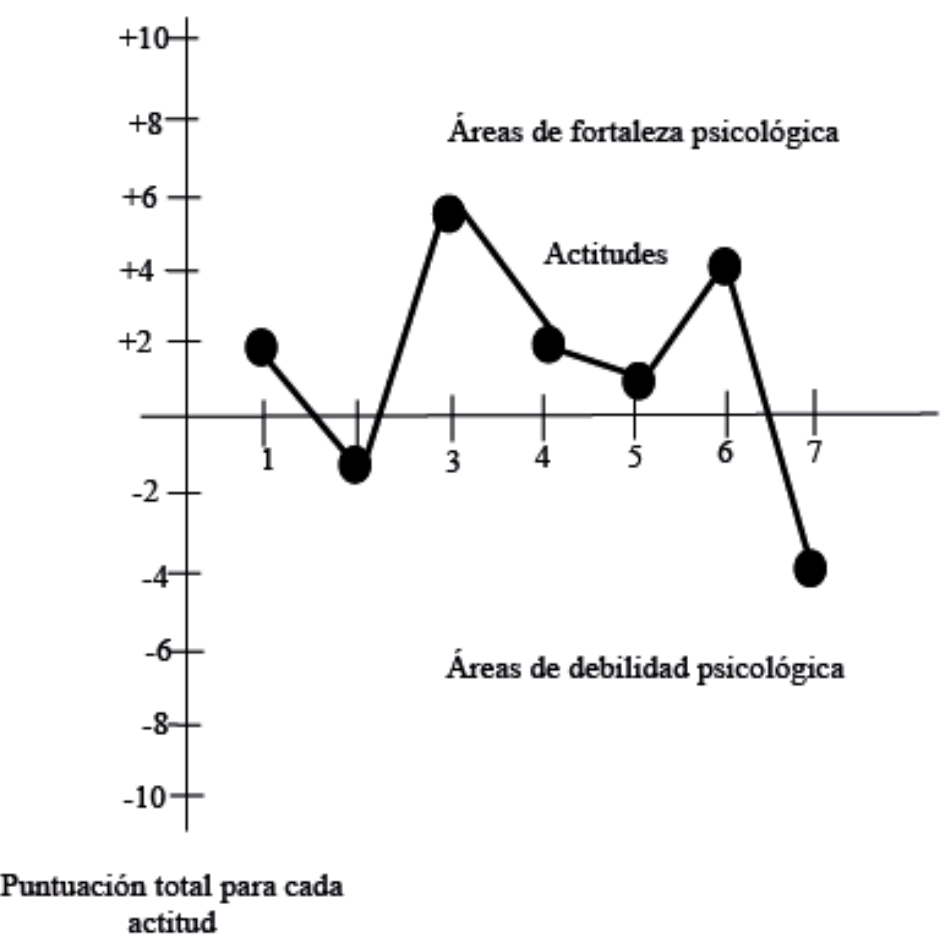

Figura 1. Perfil de actitudes disfuncionales en la evaluación pretratamiento.

derecho sobre otros (Factor 5), omnipotencia (Factor 6) y, autonomía (Factor 7), fueron considerados factores de vulnerabilidad.

En sexto lugar, se aplicaron distintas escalas para la evaluación de la Activación Conductual. Una de ellas fue Behavioral Activation for Depression Scale (BADS) (Kanter, Mulick, Busch, Berlin, \& Martell, 2007); en concreto, la adaptación al español de Barraca, Pérez-Álvarez, \& Lozano-Bleda (2011). La puntuación de la paciente en las subescalas fue de 20 en BADS-I (activación), de 32 en BADS-II (evitación-rumia), de 29 en BADS-III (afectación del trabajo/ educación) y, de 25 en BADS-IV (afectación de la vida social). Además, rellenó la Environmental Reward Observation Scale (EROS) (Armento \& Hopko, 2007), en la versión adaptada al español por Barraca y Pérez-Álvarez (2010). En esta escala, la puntuación de 19 reflejó que $M$ estaba expuesta un bajo nivel de reforzamiento positivo contingente.

Con el propósito de clarificar los valores de la paciente se emplearon la Hoja de Asesoramiento de valores, el Formulario Narrativo de Valores y, el Cuestionario de Vida Plena (VLQ-2) (Hayes et al., 2015; Wilson \& Luciano, 2002; Wilson, Sandoz, Kitchens, \& Roberts, 2010).

Para evaluar la evitación experiencial y la flexibilidad psicológica se empleó el Cuestionario de Aceptación y Acción (AQQ) (Barraca, 2004; Wilson \& Luciano, 2002). Sobre la base de la puntuación de $\mathrm{M}$ de 38 , se indicó altos niveles de evitación experiencial.

En última instancia, se le solicitó la cumplimentación de varios autorregistros durante las tareas de relajación, autoexposición, activa- 
ción conductual, detección de pensamientos automáticos, reestructuración cognitiva y exposición en imaginación.

Al finalizar la intervención terapéutica se volvieron a aplicar los cuestionarios como medida postratamiento. Asimismo, se tomaron medidas de seguimiento a los seis meses de la intervención.

\section{Diagnóstico clínico}

En base a la información recogida a raíz de la entrevista clínica se estableció que según los criterios diagnósticos del DSM-5, M padecía un TEPT de inicio demorado (American Psychiatric Association, 2013). Secundariamente a esta patología, la paciente manifestaba síntomas depresivos, agorafóbicos y de ansiedad social.

\section{Formulación clínica del caso}

\section{Hipótesis de origen}

En su origen, los problemas que $M$ presenta pueden explicarse mediante un proceso de condicionamiento clásico (Mowrer, 1960) y, a través de la teoría de Resick y Schnicke (1992) y la teoría del procesamiento emocional (Foa \& Kozak, 1986; Foa \& Rothbaum, 1998; Foa et al., 2007). Las repetidas vivencias negativas de abuso sexual experimentadas por la víctima operaron como estímulos incondicionados (EI), produciendo una respuesta incondicionada (RI) de temor y ansiedad extrema. Por contigüidad física y temporal, los estímulos neutros (EN) presentes en esa situación (p. ej., lugares donde sucedieron los abusos, condiciones ambientales y lumínicas...), se convirtieron en estímulos condicionados (EC), provocando temor y ansiedad condicionada a nivel cognitivo, fisiológico y motor. En el proceso de condicionamiento de segundo orden, los EC pudieron actuar como El emparejándose con EN (p. ej., imágenes, recuerdo de lo ocurrido...). De modo que éstos adquirieron carácter aversivo, convirtiéndose en $\mathrm{EC}$ de segundo orden y provocando también la respuesta de temor y ansiedad. A través de un proceso de generalización se explica que las respuestas de ansiedad se generalizasen a estímulos que guardaban cierto parecido (p. ej., noticias en el periódico o en la televisión acerca de abusos en menores...). En último término, especulamos que se conformó una memoria del trauma la cual incluía información sobre los estímulos $y$, las respuestas y significados asociados (Foa \& Kozak, 1986).

Por añadidura, en la génesis, la formación de esquemas nucleares sobre el acontecimiento vivido pudo desempeñar un papel fundamental (Resick \& Schnicke, 1992). Aunque, en un primer momento, estos pudieron resultar adaptativos para enfrentarse al acontecimiento, con el tiempo, se han tornado en disfuncionales. De tal forma que, estas estructuras han podido favorecer que $M$ perciba el mundo $y$ a las personas negativamente, desarrollando pensamientos irracionales relacionados con lo ocurrido y atribuciones de responsabilidad. De igual modo, han podido influir en la alteración en la manera de percibirse a sí misma como alguien vaga, incompetente e incapaz. Más aún, estas estructuras subyacen a los sentimientos de culpa y vergüenza que $M$ experimenta.

Por demás, la falta de modelos de apego seguros en la infancia, junto con un ambiente familiar caracterizado por hostilidad y violencia 
familiar y los valores sociales, característicos de un ambiente de pueblo, modularon el desarrollo de esquemas cognitivos disfuncionales ( $p$. ej., "No te puedes fiar de nadie", "El mundo es un lugar peligroso", "El grupo puede rechazarte") $y$, las reacciones de $\mathrm{M}$ ante el acontecimiento.

\section{Hipótesis de mantenimiento}

El mantenimiento de la conducta problemática también puede explicarse siguiendo los postulados de la teoría del procesamiento emocional (Foa \& Kozak, 1986; Foa \& Rothbaum, 1998; Foa et al., 2007), la teoría cognitivo-social (Resick \& Schnicke, 1992; Resick et al., 2014; Resick et al., 2002) y, los principios del condicionamiento operante (Mowrer, 1960).

Debido a que el recuerdo de la experiencia traumática y los estímulos asociados desencadenan una extrema ansiedad (RC), M evita dichos estímulos. Es más, cuando se expone a los EC (p. ej., pensamientos), $M$ emite operantes cognitivas y conductuales de escape (p. ej., intentos de bloquear los pensamientos, alejamiento del lugar, limpieza obsesiva...). De igual manera, la ansiedad anticipatoria ante diferentes situaciones así como las cogniciones y expectativas negativas sobre el mundo y las demás personas propician en M la evitación de los estímulos temidos, de las situaciones lúdicas y, de relación interpersonal. La emisión de estas conductas reducen o impiden las RC de ansiedad y los peligros temidos (reforzamiento negativo). También imposibilitan el procesamiento emocional del acontecimiento, ya que sólo se accede a una parte de la información de la memoria traumática y durante un tiempo limitado, contribuyendo a mantener las expectativas de amenaza (Bados, 2005). De forma equivalente, los esquemas de miedo propician la aparición de sesgos en la codificación, interpretación y recuperación de la información. Por esta razón, $\mathrm{M}$ no recaba información inconsistente a la almacenada en sus esquemas, la cual podría contribuir a su modificación (Foa y Kozak, 1986).

Por otro lado, la evitación de estímulos ansiógenos y la negativa a contar su experiencia originan una serie de problemas psicofisiológicos (cefaleas, dolores de espalda y espasmos musculares).

Los esquemas disfuncionales (Resick \& Schnicke, 1992) y la sintomatología característica del TEPT propician la aparición de síntomas de ansiedad social y agorafobia. Por consiguiente, $M$ reduce sus actividades gratificantes y de relación social. La emisión de estas operantes implica una disminución del reforzamiento positivo, facilitando la aparición de la depresión (Barraca \& Pérez, 2015). A su vez, la conducta depresiva propicia la merma de la autoestima y el reforzamiento de los esquemas desadaptados.

Por su parte, los esquemas latentes pueden activarse ante determinados sucesos críticos favoreciendo la aparición de distorsiones cognitivas $y$, de un estado de ánimo depresivo (Beck et al., 2012).

\section{Tratamiento}

A partir del modelo explicativo presentado, los dos objetivos generales que guiaron la intervención fueron la reducción de la sintomatología del TEPT y la extinción del patrón de 
conductas de evitación. Como objetivos secundarios se planteó la reducción de los síntomas depresivos, agorafóbicos y de ansiedad social y, el aumento de la flexibilidad psicológica.

Los objetivos terapéuticos fueron consensuados con la paciente. Para la consecución de cada objetivo se decidió aplicar técnicas de probada eficacia.

En la Tabla 1 se concretan los objetivos cognitivos y las técnicas de intervención empleadas.

En la Tabla 2 se presentan los objetivos emocionales-fisiológicos y las técnicas de intervención asociadas.

En la Tabla 3 aparecen los objetivos conductuales y las técnicas de intervención correspondientes.

\section{Procedimiento}

La intervención se llevó a cabo en un gabinete de Psicoterapia de Madrid por una Psicóloga General Sanitaria bajo la supervisión de una Psicóloga Clínica. En el tratamiento se aplicó la TCC con componentes específicos de las terapias de tercera generación (ACT y AC). La intervención consistió en catorce sesiones con una periodicidad semanal y una duración estimada de noventa minutos. A continuación, se describen las fases del tratamiento:

a) Alianza terapéutica y psicoeducación

Desde el comienzo de la terapia, se priorizó la creación de una buena alianza terapéutica. Una vez recogida suficiente información, en el marco de la TCC se explicó a la paciente el modelo de origen y mantenimiento del TEPT

Tabla 1

Relación entre objetivos cognitivos y técnicas de intervención

\section{Objetivos cognitivos}

Crear una buena alianza terapéutica.

\section{Técnicas de intervención}

Empatía, escucha activa, autenticidad, aceptación incondicional y resúmenes intercalados (Beck, Rush, Shaw y Emery, 2012). Empleo de la validación (Barraca y Pérez, 2015; Linehan, 1993).

Psicoeducación: Explicación del modelo de origen y mantenimiento del TEPT y Análisis Funcional.
Comprender el papel de los pensamientos en la génesis de estados emocionales y conductas.
(Beck et al., 2012). Biblioterapia: Capítulo tres de Ellis (1998).
Reducir la credibilidad en los esquemas negativos sobre sí misma y el mundo.

Facilitar el procesamiento emocional del suceso traumático.

Clarificación de valores personales.
Técnica de las cuatro columnas (Beck et al., 2012) y Diálogo socrático (Beck, 2011;

Beck, Emery y Greenberg, 2014; Resick et al., 2014). Reestructuración cognitiva (Bas y Andrés, 1994).

Exposición en imaginación al recuerdo traumático (Foa et al., 2007; Foa y Rothbaum, 1998).

Exposición a escuchar el audio de la narración del episodio traumático y, exposición a escribir el episodio traumático.

Cumplimentación del Formulario Narrativo de Valores (Hayes et al., 2015) y VLQ-2 (Wilson et al., 2010). Ejercicio experiencial del funeral (Wilson y Luciano, 2002). 
Tabla 2

\section{Relación entre objetivos emocionales-fisiológicos y técnicas de intervención}

\section{Objetivos emocionales-fisiológicos}

Reducir la activación fisiológica.

\section{Técnicas de intervención}

Entrenamiento en relajación muscular progresiva de Jacobson (Bernstein y Borkovec, 1983).

Entrenamiento en respiración diafragmática y respiración profunda (Labrador, 2008).

Aumentar el estado de ánimo.

Aumentar el autorrefuerzo.

Activación conductual: planificación de valiosas (Barraca y Pérez, 2015).

Entrenamiento en autorrefuerzo (Carrasco, 2008).

Reducir el sentimiento de enfado.

Diálogo socrático (Beck et al., 2014; Beck, 2011; Resick et al., 2014). (Beck et al., 2012). Biblioterapia: Capítulo tres de Ellis (1998).

Reducir el sentimiento de culpabilidad y vergüenza. Identificar y modificar sentimientos maladaptativos acerca del episodio de abuso.
Reducir la ansiedad ante el recuerdo del Exposición en imaginación al recuerdo del episodio traumático (Foa et acontecimiento de abuso.

Aceptación psicológica de los recuerdos.

Disminuir la evitación experiencial. al., 2007; Foa y Rothbaum, 1998)

Exposición al audio de la narración del episodio traumático. Exposición a escribir el episodio traumático.

\section{Tabla 3}

Relación entre objetivos conductuales y técnicas de Intervención

\section{Objetivos conductuales}

Extinción de las conductas de evitación, seguridad y dependencia.

Ampliar el repertorio conductual.

Aumentar la percepción de autoeficacia.

Comenzar a vivir implicándose en actividades congruentes con sus valores.

\section{Técnicas de intervención}

Auto-exposición graduada. (Zayfert y Becker, 2008).

Conseguir la implicación de la paciente y su hija en

Activación conductual: planificación de actividades valiosas (Barraca y Pérez, 2015).

el cumplimiento de las tareas propuestas en la AC.

Contrato conductual (Barraca y Pérez, 2015).

Implantar estímulos discriminativos para Control estimular (Carrasco, 2008).

despertarse.

Extinción de las conductas de evitación de situaciones relacionadas con el acontecimiento traumático.

Ampliar el repertorio conductual ante situaciones relacionadas con el acontecimiento traumático.
Auto-exposición in-vivo (Foa et al., 2007; Foa y Rothbaum, 1998; Zayfert y Becker, 2008). 
y, nuestra primera hipótesis sobre el análisis funcional de su caso. También se le expuso el funcionamiento de la ansiedad en el triple sistema de respuesta (Clark \& Beck, 2012). Con el objetivo de que $M$ tomase conciencia del resultado paradójico de sus esfuerzos de control mental realizamos el ejercicio experiencial del pastel de chocolate (Hayes et al., 2015).

b) Diálogo socrático y técnicas de reatribución

Durante las primeras sesiones, $M$ expresó sentimientos de culpabilidad y vergüenza con respecto al ASI. Estas emociones fueron trabajadas a través del diálogo socrático (Beck et al., 2014; Beck, 2011; Resick et al., 2014) y técnicas de reatribución (Beck et al., 2012).

c) Entrenamiento en técnicas de relajación

Debido a los altos niveles de ansiedad se entrenó a $M$ en técnicas de relajación. Por un lado, se empleó la relajación muscular progresiva de Jacobson (Bernstein \& Borkovec, 1983) $y$, por otro, se le enseñó la respiración diafragmática y la respiración profunda (Labrador, 2008).

\section{d) Autoexposición gradual}

Para tratar las conductas agorafóbicas y síntomas de ansiedad social se utilizó la exposición. En ese momento, se proporcionaron a la paciente instrucciones específicas con la meta de realizar las tareas de exposición. Especialmente, se hizo hincapié en la importancia de la implicación atencional durante el procedimiento (Echeburúa, de Corral, \& Ortiz, 2008; Foa \& Kozak, 1986; Jaycox, Foa, \& Morral, 1998;
Pérez \& Borrás, 2003). De forma equivalente, se incentivó a M para que, en tales circunstancias, se implicase en conductas alternativas a la evitación.

Por último, a lo largo de las sesiones se solventaron las dificultades que la paciente encontraba durante los ejercicios. Por ejemplo, a raíz de la alegación de $\mathrm{M}$ sobre su rápido caminar, se decidió emplear la metáfora de esquiar a fin de que tomase conciencia de la importancia de atender al momento presente (Hayes et al., 2015).

e) Clarificación de valores personales y activación conductual

Con miras a que la paciente sacase a relucir sus valores se le solicitó que cumplimentara el Formulario Narrativo de Valores y el VLQ-2 (Hayes et al., 2015; Wilson et al., 2010). De igual modo, en la sesión se llevó a cabo el ejercicio experiencial del funeral (Wilson \& Luciano, 2002).

Tras la especificación de los valores en las diferentes áreas vitales, se instruyó a la paciente en el modelo de AC, explicándole el análisis funcional de la depresión (Barraca \& Pérez, 2015). Después, elaboramos un horario de actividades valiosas. Al comienzo de cada sesión, se revisaba con la paciente el cumplimiento de actividades, se le suministraba retroalimentación correctiva y, planificábamos nuevas tareas para la próxima semana.

Por otra parte, teniendo en cuenta que $M$ tenía dificultades para ponerse en marcha y realizar las actividades, se decidió contar con el apoyo y supervisión de su hija. Con la intención de conseguir el compromiso de ambas fir- 
mamos un contrato conductual (Barraca \& Pérez, 2015). También determinamos emplear el control estimular junto con el entrenamiento en autorrefuerzo para aumentar la probabilidad de que $M$ ejecutase las actividades previstas (Carrasco, 2008).

\section{f) Reestructuración cognitiva}

En un primer momento, a través de un ejemplo y la lectura del capítulo tres del libro de Ellis (1998) se explicó a la paciente el modelo $A B C$.

Después de revisar la técnica de las cuatro columnas (Beck et al., 2012), se introdujo la reestructuración cognitiva (Bas \& Andrés, 1994). Con el propósito de reestructurar los pensamientos y creencias irracionales se realizó el contraste lógico, empírico y, en su caso, adaptativo de sostener tales cogniciones disfuncionales.

Finalmente, convenimos con la paciente seguir adelante con la detección y disputa de sus pensamientos automáticos. De la misma manera, como tarea para casa se le asignó que reestructurase tres de sus esquemas más arraigados "Yo soy vaga, incompetente e incapaz", “El mundo es un lugar peligroso donde te pueden pasar cosas malas" $y$, “El grupo puede rechazarte".

\section{g) Exposición en imaginación}

El núcleo del tratamiento versó en la exposición en imaginación al episodio de abuso (Foa et al., 2007; Foa \& Rothbaum, 1998). Al comienzo de la octava sesión, $M$ se mostró ambivalente con respecto a someterse a este procedimiento. Por tal motivo, retomamos la tarea de clarificación de valores para contextualizar la tarea de exposición. Como tareas entre sesiones, $\mathrm{M}$ escuchó el audio del relato del acontecimiento.

En la novena sesión, la paciente reportó una exacerbación de la sintomatología del TEPT y de los síntomas depresivos. Durante esa semana, la paciente abandonó algunas de las actividades de la AC. Además, nos comentó que había recuperado una nueva imagen del episodio.

En último lugar, en la décima sesión se animó a la paciente a confrontar la imagen recuperada a través de la técnica de la cámara lenta (Foa \& Rothbaum, 1998).

h) Autoexposición in vivo a situaciones evitadas relacionadas con el ASI

En la duodécima sesión se construyó una jerarquía de situaciones evitadas debido a que le suscitaban ansiedad, recuerdos e imágenes sobre el acontecimiento de ASI.

Por voluntad propia, la paciente se iba exponiendo exitosamente a más situaciones de las estipuladas en las sesiones.

i) Cierre de terapia

En la sesión trece, se acordó con la paciente una cita al cabo de dos semanas. En la decimocuarta sesión, $\mathrm{M}$ continuaba con sus actividades diarias. Lo que es más, se había implicado en nuevas tareas. En ese tiempo, la paciente proseguía realizando las exposiciones con bajos niveles de ansiedad y desplegando nuevos repertorios de conducta. 
En otro momento de la sesión, como tarea de exposición, la paciente nos leyó un relato que había escrito acerca del episodio de abuso.

Para concluir, cumplimentó los distintos cuestionarios de evaluación, leyó la hoja informativa para participar en el estudio y, firmó el consentimiento informado. A partir de entonces, se inició el periodo de seguimiento.

En la Tabla 4 se presenta un cronograma donde se especifican las técnicas de intervención aplicadas en cada sesión.

\section{Resultados}

El análisis de los resultados se realizó teniendo presentes los objetivos del programa de intervención.

En lo que atañe a los hallazgos obtenidos en la evaluación postratamiento en la Escala
Global de Gravedad de los Síntomas del TEPT se corroboró que la sintomatología característica del trastorno se había eliminado. Así, la puntuación en la escala global mermó de 31 a 7. En las escalas específicas la disminución se produjo de 14 en evitación a 3, de 9 en reexperimentación a 2 y, de 8 en aumento de la activación a 2. En las medidas de seguimiento, la puntuación de la paciente en la escala global se redujo a 4. Por su parte, en las escalas específicas $M$ obtuvo un puntaje de 0 en evitación, de 2 en reexperimentación y de 2 en aumento de la activación. Más aún, a partir de la reducción postratamiento de los puntajes en la escala de Inadaptación, de Echeburúa, se apuntaba a una menor inadaptación de la paciente en sus diferentes áreas vitales. De esta forma, las puntuaciones disminuyeron de 27 a

Tabla 4

Cronograma de técnicas de Intervención aplicadas en cada sesión

\begin{tabular}{|c|c|}
\hline Sesiones & Técnicas de intervención \\
\hline $1,2,3,6$ & $\begin{array}{l}\text { Psicoeducación. } \\
\text { Análisis de Decisión. }\end{array}$ \\
\hline $1-14$ & Diálogo socrático. \\
\hline $\begin{array}{l}2,3,5,6,7,8,9,10,11 \\
\text { 2. } \\
3 . \\
5 . \\
6 . \\
7 .\end{array}$ & $\begin{array}{l}\text { Relajación muscular progresiva de Jacobson (R. J) y Técnicas de respiración (R). } \\
\text { R. J. Dieciséis grupos musculares. R. Diafragmática. } \\
\text { R. J. Siete grupos musculares. } \\
\text { R. J. Cuatro grupos musculares. } \\
\text { R. J. Condicionada. R. Profunda. } \\
\text { R. Diafragmática. R. Profunda. }\end{array}$ \\
\hline $3-8$. & Auto-exposición graduada. \\
\hline $\begin{array}{l}4 . \\
4 \text { y } 5 .\end{array}$ & $\begin{array}{l}\text { Formulario Narrativo de Valores y VLQ-2. Ejercicio experiencial del Funeral. } \\
\text { Entrenamiento en autorrefuerzo. Control estimular. Ejercicios de auto-observación de Rehm. }\end{array}$ \\
\hline $\begin{array}{l}4-14 . \\
6 \text { y } 7 .\end{array}$ & $\begin{array}{l}\text { Activación conductual: planificación de actividades valiosas. } \\
\text { Reestructuración cognitivo-conductual-sistemática. Psicoeducación: Modelo ABC. }\end{array}$ \\
\hline $\begin{array}{c}8-11 . \\
12-14 .\end{array}$ & $\begin{array}{l}\text { Exposición en imaginación al episodio de abuso. } \\
\text { Auto-exposición in-vivo a las situaciones relacionadas con el episodio de abuso. }\end{array}$ \\
\hline
\end{tabular}


8 en la puntuación total, de 6 a 3 en trabajo, de 5 a 1 en vida social, de 4 a 1 en tiempo libre, de 4 a 1 en relaciones de pareja, de 4 a 1 en vida familiar $y$, de 4 a 1 en la escala global. A los seis meses del tratamiento, las puntuaciones se redujeron a 5 en la puntuación total, a 1 en trabajo, a 1 en vida social, a 2 en tiempo libre, a 0 en relación de pareja, a 0 en vida familiar $y$, a 1 en escala global.

Con respecto a la sintomatología depresiva, en el BDI-Il se pasó de una puntuación de 32 , representativa de una depresión severa, a una de 5, indicativa de ausencia de depresión. Durante el tratamiento, se contempló que la mejoría se produjo especialmente a partir de la sexta sesión. Sin embargo, durante la novena semana de tratamiento se apreció una exacerbación de la sintomatología depresiva. Este deterioro tuvo lugar durante la aplicación del procedimiento de exposición. Durante esa se- mana, la paciente también informó de un aumento de pensamientos e imágenes intrusivas acerca del acontecimiento traumático.

Las puntuaciones de la paciente en el cuestionario BDI-II a lo largo del tratamiento aparecen reflejadas en la Figura 3.

A los seis meses de la intervención, el puntaje de la paciente en el $\mathrm{BDI}-\mathrm{Il}$ de 5 reveló el mantenimiento de los cambios en la sintomatología depresiva.

Cuando se trata de las medidas de aceptación psicológica, en el $\mathrm{AQQ}$, la puntuación disminuyó de 38 a 25. En el seguimiento, la puntuación descendió a 18. El decremento de la puntuación en esta escala reflejó una mayor aceptación de las experiencias (Barraca, 2004; Wilson \& Luciano, 2002).

En lo que se refiere a los valores personales, a virtud de la reducción de las puntuaciones del VLQ-2 en la evaluación postratamiento y

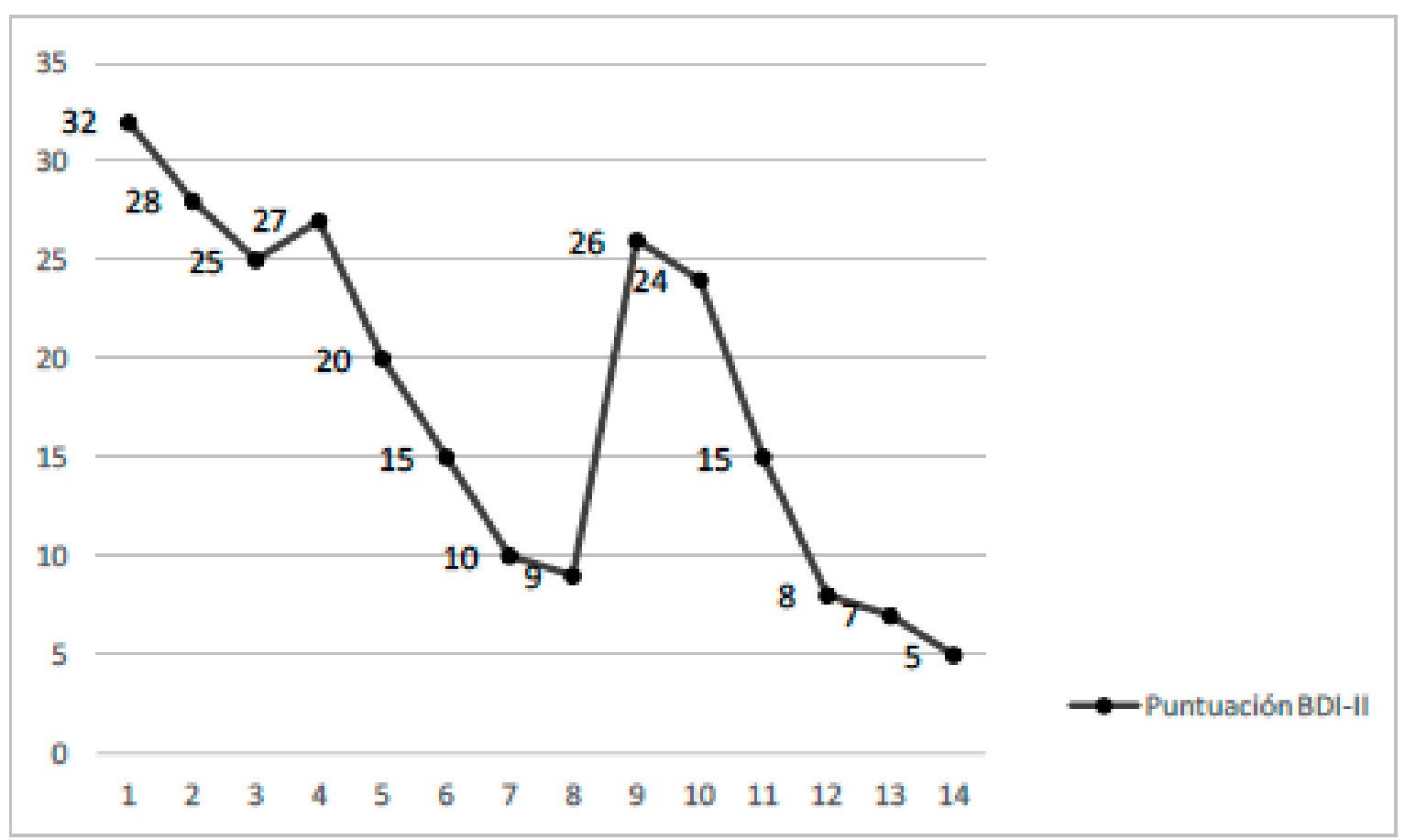

Figura 2. Puntuación en el BDI-II durante las semanas de tratamiento. 
en las medidas de seguimiento, se señala una discrepancia menor en todas las áreas vitales. En especial, en las áreas objeto de tratamiento como relaciones familiares, matrimonio, ser padres, amistad y relaciones, educación, cuidado físico y salud y, diversión. Las puntuaciones de discrepancia pretratamiento, postratamiento y seguimiento en las diferentes áreas vitales se muestran en la Tabla 5.

En cuanto al STAl, se observó una importante mejoría en las dos escalas del instrumento. Así, se produjo una reducción en las puntuaciones de 38 a 15 en ansiedad estado y, de 39 a 28 en ansiedad rasgo. En base al baremo de mujeres adultas, en el primer caso supuso el cambio del percentil 95 al 50. Mientras que, en el segundo caso implicó la transición del percentil 90 al 70 (Spielberger et al., 2011). A los seis meses de la intervención, el puntaje en el
STAI en ansiedad estado fue de $10 \mathrm{y}$ en ansiedad rasgo de 25. Este cambio supuso el paso del percentil 50 al 23 en ansiedad estado y de 70 a 60 en ansiedad rasgo (Spielberger et al, 2011).

En relación con las medidas de autoestima, la puntuación obtenida en el pretratamiento fue de 28. Pese a no haber obtenido una puntuación excesivamente baja en el pretratamiento, se apreció una mejoría en la imagen que $\mathrm{M}$ mantenía de sí misma debido a que obtuvo una puntuación postratamiento de $34 \mathrm{y}$ una puntuación en el seguimiento de 35 .

Tomando como base la evaluación postratamiento en el DAS se obtuvo que las puntuaciones en los factores se modificaron de -2 a 2 en aprobación (Factor 1), de -5 a 6 en amor (Factor 2), de 1 a 8 en ejecución (Factor 3), de -2 a -1 en perfeccionismo (Factor 4), de -3 a 3 en

\section{Tabla 5}

Puntuaciones pretratamiento y postratamiento de discrepancia entre las áreas vitales valiosas y su nivel de acción en cada ámbito

\begin{tabular}{|c|c|c|c|}
\hline Valores & $\begin{array}{c}\text { Puntuación de } \\
\text { discrepancia } \\
\text { pretratamiento }\end{array}$ & $\begin{array}{c}\text { Puntuación de } \\
\text { discrepancia } \\
\text { postratamiento }\end{array}$ & $\begin{array}{c}\text { Puntuación de } \\
\text { discrepancia } \\
\text { seguimiento (6 meses) }\end{array}$ \\
\hline Relaciones familiares & 4 & 2 & 0 \\
\hline Ser padres & 6 & 2 & 0 \\
\hline Amistad y relaciones sociales & 6 & 1 & 1 \\
\hline Educación & 7 & 3 & 3 \\
\hline Diversión & 6 & 2 & 1 \\
\hline Cuidado físico/Salud & 3 & 1 & 0 \\
\hline Vida en comunidad & 8 & 2 & 3 \\
\hline Medio ambiente/Sostenibilidad & 8 & 5 & 2 \\
\hline Arte/Belleza & 3 & 2 & 3 \\
\hline
\end{tabular}


derecho sobre los otros (Factor 5), de 0 a 1 en omnipotencia (Factor 6 ) y, de -8 a 6 en autonomía (Factor 7). En la Figura 3 aparece representado el Perfil de Actitudes Disfuncionales de $M$ en la evaluación postratamiento.

A los seis meses de la intervención, la puntuación de $M$ en los factores del DAS fue de 4 en aprobación (Factor 1), 6 en amor (Factor 2), 9 en ejecución (Factor 3), 0 en perfeccionismo (Factor 4), 3 en derecho sobre los otros (Factor 5), 2 en omnipotencia (Factor 6) y 8 en autonomía (Factor 7). En la Figura 4 se muestra el Perfil de Actitudes Disfuncionales de $M$ en el seguimiento.

En último lugar, atendiendo a las medidas postratamiento y de seguimiento de la activa- ción conductual, las puntuaciones en las escalas específicas aumentaron de 20 a 37 a 40 en BADS-I (activación), disminuyeron de 32 a 10 a 8 en BADS-II (evitación-rumia), de 29 a 6 a 4 en BADS-III (afectación del trabajo/educación) y, de 25 a 5 a 3 en BADS-IV (afectación de la vida social). En cuanto a su puntuación en el EROS, esta aumentó de 19 a 35. A los seis meses, la puntuación de $M$ en esta escala fue de 43 . Este incremento supuso el cambio del percentil 10 al 90 en la población general (Barraca y Pérez, 2015).

En la Figura 5 se recogen las diferencias entre las medidas pretratamiento, postratamiento y seguimiento en cada uno de los autoinformes aplicados.

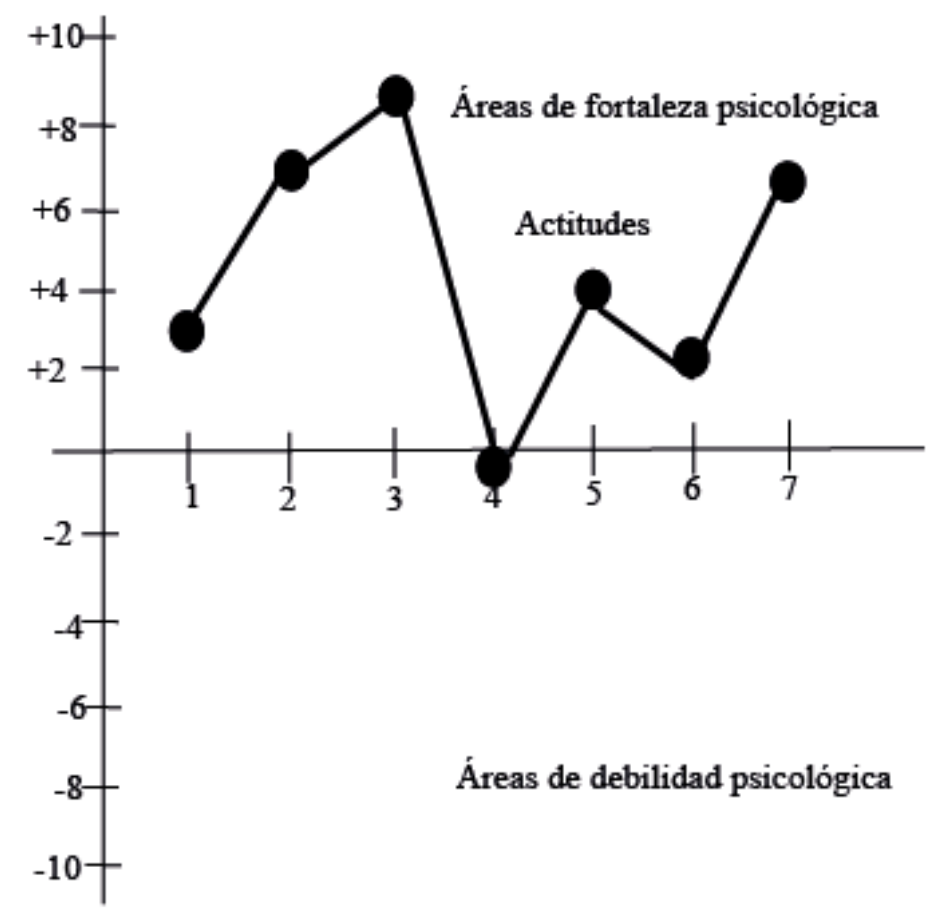

Puntuación total para cada actitud

Figura 3. Perfil de actitudes disfuncionales en la evaluación postratamiento. 


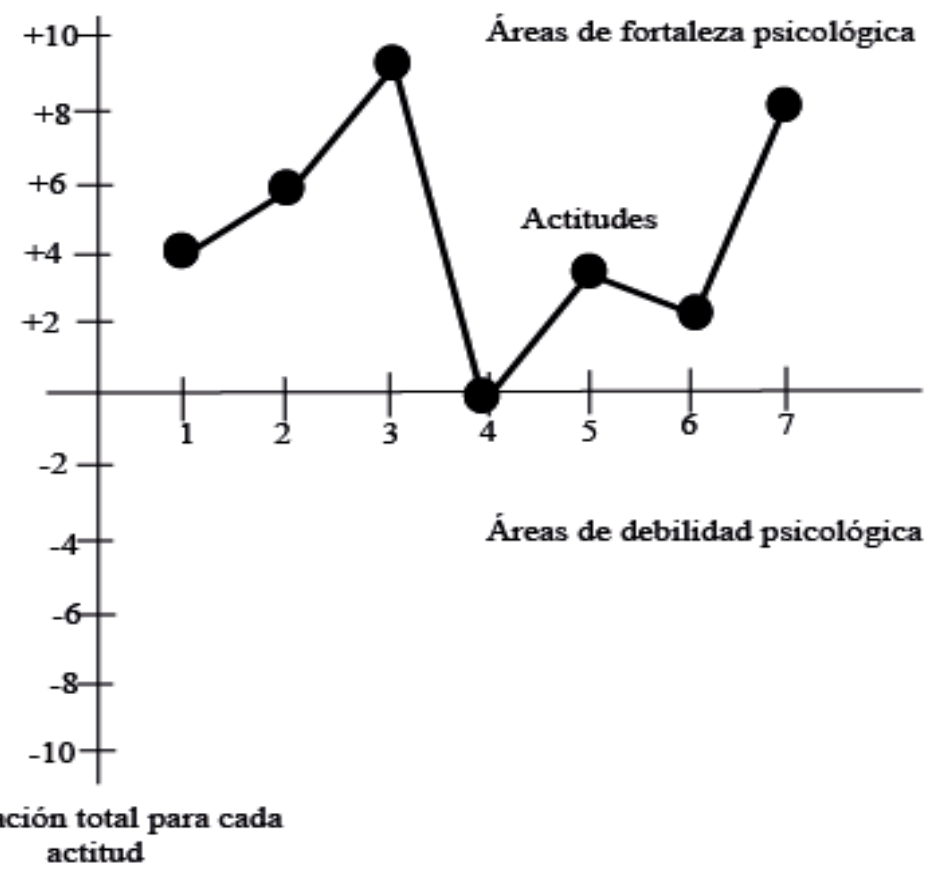

Figura 4. Perfil de actitudes disfuncionales en el seguimiento.

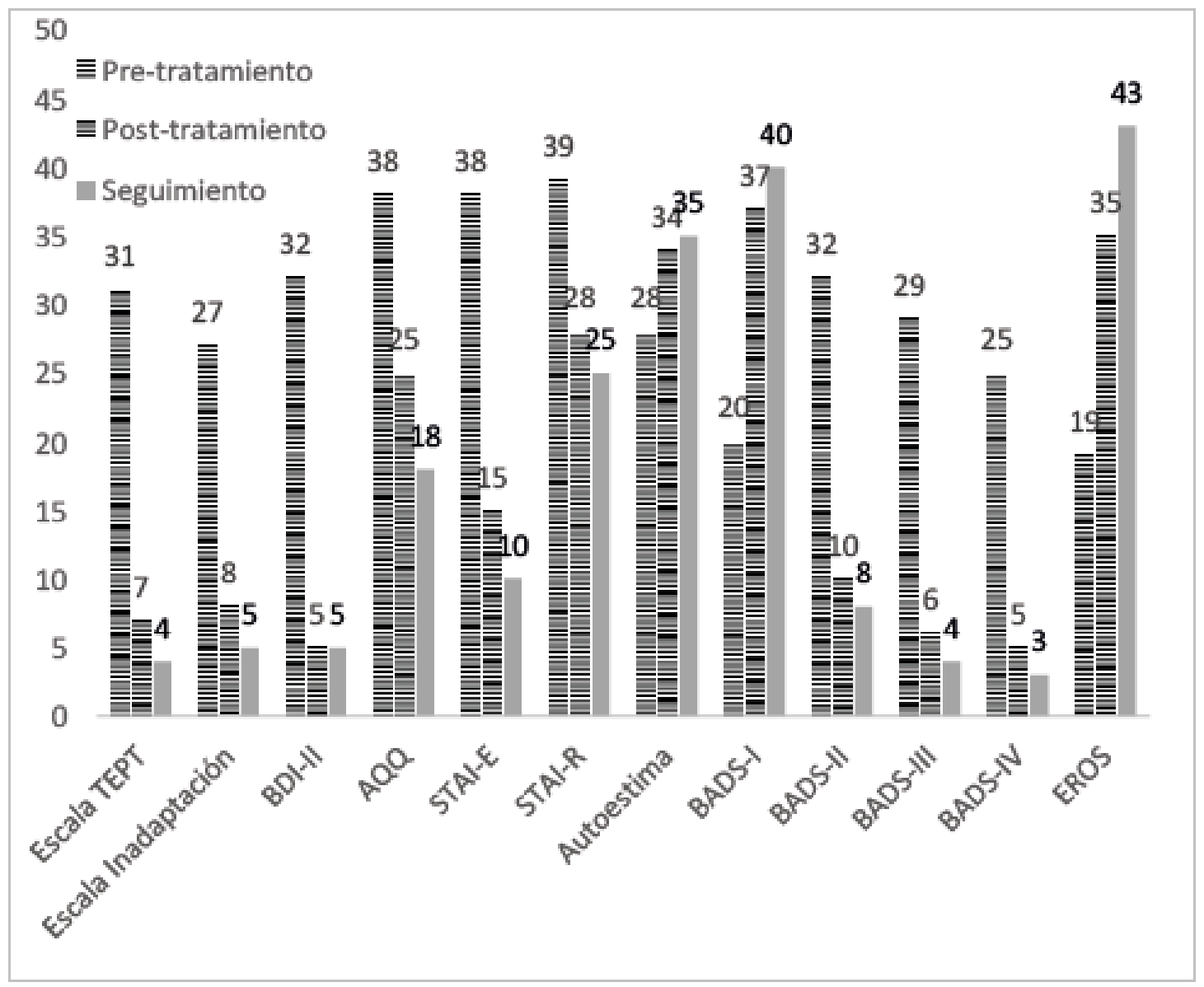

Figura 5. Puntuaciones pretratamiento, postratamiento y seguimiento en los autoinformes empleados. 


\section{Discusión}

A partir de los resultados obtenidos, se aprecia que la combinación terapéutica (TCC+ACT+AC), fue eficaz al lograr la remisión de la sintomatología del TEPT y síntomas depresivos, agorafóbicos y de ansiedad social. De esta manera, se observa una mejora en la sintomatología general de la paciente y en su funcionamiento en las diferentes áreas vitales.

Para empezar, se logró la remisión de sintomatología del TEPT tanto en las medidas postratamiento como en el periodo de seguimiento. Así, se observa un mantenimiento de los resultados del tratamiento. Es más, la paciente refirió haber vuelto a experimentar recuerdos acerca del acontecimiento a los seis meses del tratamiento. No obstante, declaró que ya no le suponían una perturbación en su vida. De esta forma, se corrobora que $\mathrm{M}$ ha cambiado la forma de relacionarse con sus experiencias privadas.

En segundo lugar, a lo largo del tratamiento, a partir de los resultados del BDI-II, se ha contemplado una disminución paulatina de los síntomas depresivos. En particular, el alivio de la sintomatología se produjo a partir de la sexta sesión, tras tres semanas de aplicar la AC. De forma que la mejoría podría atribuirse a la mayor implicación de la paciente en actividades para ella valiosas. No obstante, a pesar de la mejora inicial, a partir de la novena sesión se apreció un empeoramiento de la depresión, coincidiendo con la aplicación de la exposición en imaginación. En este momento del tratamiento, el deterioro del estado de ánimo resulta congruente con la literatura sobre la exacerbación de la sintomatología durante la apli- cación de este procedimiento (Foa et al., 2007; Rothbaum et al., 2003). Si bien, acorde con los hallazgos de estudios previos, no parece que este empeoramiento impidiera la respuesta al tratamiento (Foa, Zoellner, Feeny, Hembree, \& Alvarez-Conrad, 2002; Joseph \& Gray, 2008).

Tomando en cuenta los descubrimientos procedentes de los métodos de evaluación propios de la AC, tras la intervención, tanto el número de alicientes del entorno de $\mathrm{M}$ como su capacidad para incurrir en conductas aumentaron. Por otra parte, la reducción de la puntuación de $M$ en la escala de evitación/ rumia del BADS apoya los cambios cognitivos acaecidos.

Creemos que el valor principal de este estudio recae en la formulación clínica del caso, la aplicación de la filosofía de la ACT, la AC y la clarificación de valores.

Primeramente, el análisis funcional ha proporcionado una perspectiva idiosincrática, desde la cual comprender la génesis, desarrollo y mantenimiento de la problemática de la paciente. Asimismo, ha servido para orientar las decisiones sobre el tratamiento.

En segundo lugar, como criterios para valorar la eficacia del tratamiento no sólo se tuvo en cuenta la reducción de la sintomatología sino que también se prestó atención a si la paciente había conseguido recuperar el significado de su vida (Pérez-Álvarez, 2014). En este sentido, tradicionalmente, la eficacia de los tratamientos para el TEPT se ha medido en función de la reducción de síntomas. No obstante, aunque la reducción de la sintomatología pueda ser un objetivo importante, el bienestar va más allá. El bienestar incluye la satisfacción con la vida, 
el afecto positivo $y$, un bajo afecto negativo (Diener, 2000). Además, M acudía a terapia con la intención de recuperar el sentido de su vida. En esta línea, la demanda expresa de la paciente fue que ella quería "reorientar su sentido vital". En cierta manera, esta petición denota un problema existencial, el cual habría sido difícil de abordar sin recurrir a la clarificación de los valores personales.

En tercer lugar, en la intervención, mediante la AC se incentivó a M para comenzar a vivir una vida valiosa aunque la ansiedad, pensamientos y sentimientos indeseables pudieran estar presentes. Así, como remarcan PáezBlarrina, Gutiérrez-Martínez, Valdivia-Salas y Luciano-Soriano (2006) el dolor y el sufrimiento que implica la transición por un proceso terapéutico podría justificarse si está en una dirección acorde con los valores del cliente. Por añadidura, el trabajo explícito de los valores durante la terapia pudo incrementar la motivación hacia el tratamiento (Wilson \& Murrell, 2004). En especial, la motivación en el contexto de la exposición. En este sentido, cuando $\mathrm{M}$ se mostró reacia a la exposición en imaginación al episodio de abuso se recurrió al ejercicio de clarificación de valores. Así, fue fundamental contextualizar la exposición como una tarea importante para acercarse hacia las áreas vitales para ella valiosas.

Yendo más allá, el tratamiento aplicado podría considerarse prometedor con vistas a aumentar la adherencia a la exposición para el TEPT. De esta manera, en nuestra intervención, primero se trabajó con la paciente la disposición a aceptar sus experiencias privadas internas mediante la realización de las tareas de au- toexposición y, el cumplimiento del horario de actividades valiosas de la AC. Una vez que M exhibió un repertorio conductual más amplio y dio indicios de mayor aceptación psicológica, se le propuso realizar la exposición en imaginación al episodio traumático. El excelente cumplimiento de los ejercicios de exposición y, la adherencia a este procedimiento podría atribuirse al acicate de la aceptación experiencial, pues se ha observado que esta variable interfiere en la exposición (Jaycox et al., 1998).

Por último, este trabajo al tratarse de un estudio de caso único $A B$, por su naturaleza, presenta limitaciones que no deberían pasar desapercibidas (León \& Montero, 2003). En primer lugar, no puede negarse la existencia de variables extrañas y ajenas al tratamiento susceptibles de estar influyendo en los resultados ( $p$. ej., la paciente inició actividades valiosas como taichí). Entre otras limitaciones, se podría haber mejorado el procedimiento de evaluación por medio de la medición de la variable de regulación emocional (Hervás \& Jódar, 2008). La consideración de esta variable habría permitido valorar la conveniencia de aplicar técnicas orientadas a la regulación emocional. Asimismo, sería interesante haber registrado la evolución de la sintomatología del TEPT a lo largo del tratamiento. De este modo, serían necesarias futuras investigaciones, las cuales replicasen este tipo de tratamientos en estudios más controlados experimentalmente, con mayor número de sujetos y realizando evaluaciones más exhaustivas.

Finalmente, se estima necesario proseguir en la investigación para mejorar el abordaje del TEPT valiéndose de la combinación de los 
procedimientos que ofrecen la TCC y las orientaciones contextuales. Esta combinación podría contribuir a mejorar los resultados de la terapia de exposición, a fortalecer la adherencia a los tratamientos, a tratar simultáneamente trastornos comórbidos y, a generalizar los éxitos terapéuticos a otros ámbitos vitales (Kashdan \& Rottenberg, 2010; Orsillo et al., 2004). En definitiva, estos abordajes podrían traducirse en una mayor tolerancia al sufrimiento inherente de la existencia humana y en una mejora de la calidad de vida.

A raíz de lo expuesto anteriormente, teniendo en mente que el objetivo de todo psicólogo clínico reside en incrementar la calidad de vida de sus pacientes, se propone que la combinación de la TCC con componentes de clarificación de valores y la $A C$ podría ser una manera más funcional de abordar la sintomatología del TEPT. En este sentido, se trataría no solo de reducir los síntomas sino también de promover su aceptación y animar al paciente a retomar su vida en aras de sus valores.

\section{Referencias}

American Psychiatric Association. (2013). Guía de consulta de los criterios diagnósticos del DSM-5. Madrid: Editorial Médica Panamericana.

American Psychological Association (2010). Publication manual of the American Psychological Association (6. ${ }^{\mathrm{a}}$ ed.). Washington, DC: Autor.

Armento, M. E., \& Hopko, D. R. (2007). The environmental reward observation scale (EROS): Development, validity, and reliability. Behavior Therapy, 38, 107-119.

Ayala, J. L., \& Ochotorena, J. P. (2004). Trastorno por estrés postraumático en víctimas de situaciones traumáticas. Psicothema, 16, 4549.
Bados, A. (2005). Trastorno por estrés postraumático. Recuperado de http://diposit. ub.edu/dspace/bitstream/2445/356/1/117. pdf

Báguena, Ma. J. (2001). Tratamientos psicológicos eficaces para el estrés post-traumático. Psicothema, 13, 479-492.

Barraca, J. (2004). Spanish adaptation of the acceptance and action questionnaire (AAQ). International Journal of Psychology and Psychological Therapy, 4, 505-515.

Barraca, J. (2010). Aplicación de la activación conductual en un paciente con sintomatología depresiva. Clínica y Salud, 21, 183-197.

Barraca, J., Pérez-Álvarez, M., \& Lozano-Bleda, J. H. (2011). Avoidance and activation as keys to depression: Adaptation of the behavioral activation for depression scale in a spanish simple. The Spanish Journal of Psychology, 14, 998-1009.

Barraca, J., \& Pérez-Álvarez, M. (2010). Adaptación española del Environmental Reward Observation Scale (EROS). Ansiedad y Estrés, 16, 95-107.

Barraca, J., \& Pérez-Álvarez, M. (2015). Activación conductual para el tratamiento de la depresión. Madrid: Síntesis.

Bas, F., \& Andrés, V. (1994). Terapia cognitivoconductual de la depresión: un manual de tratamiento. Madrid: Fundación Universidad-Empresa.

Beck, A. T., Emery, G., \& Greenberg, R. (2014). Trastornos de ansiedad y fobias. Una perspectiva cognitiva (Trad. M. Bernardo). Bilbao: Desclée de Brouwer. (Original de 1985).

Beck, A. T., Rush, A. J., Shaw, B. F., \& Emery, G. (2012). Terapia cognitiva de la depresión (20.a ed.) (Trad. S. Pabón). Bilbao: Desclée de Brouwer. (Original de 1983).

Beck, A. T., Steer, R. A., \& Brown, G. K. (2011). Inventario de Depresión de Beck-II (ed. rev. J. Sanz, \& C. Vázquez). Madrid: Pearson.

Beck, J. (2011). Cognitive behavior therapy. Basics and beyond. New York: Guilford Press.

Becker, C. B., \& Zayfert, C. (2001). Integrating DBT-based techniques and concepts to facilitate exposure treatment for PTSD. Cognitive and Behavioral Practice, 8, 107-122.

Bernstein, D., \& Borkovec, T. (1983). Entrena- 
miento en relajación progresiva (Trad. L. M.

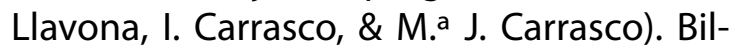
bao: Desclée de Brouwer. (Original de 1973). Bianchi-Salguero, J. M., \& Muñoz-Martínez, A. M. (2014). Activación conductual: Revisión histórica, conceptual y empírica. Psychologia: Avances de la Disciplina, 8, 83-93.

Boon, S., Steele, K., \& Van Der Hart, O. (2014). Vivir con disociación traumática. Entrenamiento de habilidades para pacientes y terapeutas (Trad. A. Colodrón). Bilbao: Desclée de Brouwer. (Original de 2011).

Brewin, C. R. (1989). Cognitive change processes in psychotherapy. Psychological Review, 96, 379-394.

Brewin, C. R., Dalgleish, T., \& Joseph, S. (1996). A dual representation theory of posttraumatic stress disorder. Psychological Review, 103, 670-686.

Cannon, E. A., Bonomi, A. E., Anderson, M. L., Rivara, F. P., \& Thompson, R. S. (2010). Adult health and relationship outcomes among women with abuse experiences during childhood. Violence and Victims, 25, 291-305.

Carrasco, M. J. (2008). Técnicas de autocontrol. En F. J. Labrador (Coord.), Técnicas de modificación de conducta (pp. 379-399). Madrid: Pirámide.

Ciarrochi, J., \& Bailey, A. (2008). A cbt practitioner's guide to act. How to bridge the gap between cognitive behavioral therapy and acceptance and commitment therapy. Oakland, CA: New Harbinger Publications.

Clark, D. A., \& Beck, A. T. (2012). Terapia cognitiva para trastornos de ansiedad (Trad. J. Aldekoa). Bilbao: Desclée de Brouwer. (Original de 2010).

Diener, E. (2000). Subjective well-being: The science of happiness and a proposal for a national index. American Psychologist, 55, 34-43.

DiLillo, D. (2001). Interpersonal functioning among women reporting a history of childhood sexual abuse: Empirical findings and methodological issues. Clinical Psychology Review, 21, 553-576.

Echeburúa, E., de Corral, P., Amor, P. J., Zubizarreta, I., \& Sarasua, B. (1997). Escala de Gra- vedad de Síntomas del Trastorno de Estrés Postraumático: propiedades psicométricas. Análisis y Modificación de Conducta, 23, 503-526.

Echeburúa, E., de Corral, P., \& Fernández-Montalvo, J. (2000). Escala de Inadaptación (EI): propiedades psicométricas en contextos clínicos. Análisis y Modificación de Conducta, 26, 325-340.

Echeburúa, E., de Corral, P., \& Ortiz, C. (2008). Técnicas de exposición. En F. J. Labrador (Coord.), Técnicas de modificación de conducta (pp. 261-279). Madrid: Pirámide.

Echeburúa, E., de Corral, P., Zubizarreta, I., \& Sarasua, B. (1995). Trastorno de estrés postraumático crónico en víctimas de agresiones sexuales. A Coruña: Fundación Paideia.

Ehlers, A., \& Clark, D. M. (2000). A cognitive model of posttraumatic stress disorder. Behaviour Research and Therapy, 38, 319-345.

Ellis, A. (1998). Razón y emoción en psicoterapia (5. a ed.) (Trad. A. Ibáñez). Bilbao: Desclée de Brouwer. (Original de 1980).

Ferro, R. (2000). Aplicación de la terapia de aceptación y compromiso en un ejemplo de evitación experiencial. Psicothema, 12, 445-450.

Foa, E. B., Gillihan, S. J., \& Bryant, R. A. (2013). Challenges and successes in dissemination of evidence-based treatments for posttraumatic stress: Lessons learned from prolonged exposure therapy for PTSD. Psychological Science in The Public Interest, 14, 65-111.

Foa, E. B., Hembree E. A., \& Rothbaum, B. O. (2007). Prolonged exposure therapy for PTSD. Emotional processing of traumatic experiences. New York: Oxford University Press.

Foa, E. B., \& Kozak, M. J. (1986). Emotional processing of fear: Exposure to corrective information. Psychological Bulletin, 99, 20-35.

Foa, E. B., \& Meadows, E. A. (1997). Psychosocial treatments for posttraumatic stress disorder: A critical review. Annual Review of Psychology, 48, 449-480.

Foa, E. B., \& Rothbaum, B. O. (1998). Treating the trauma of rape: Cognitive-behavioral therapy for PTSD. New York: Guilford Press.

Foa, E. B., Zoellner, L. A., Feeny, N. C., Hem- 
bree, E. A., \& Alvarez-Conrad, J. (2002). Does imaginal exposure exacerbate PTSD symptoms? Journal of Consulting and Clinical Psychology, 70, 1022-1028.

Follette, V. M., Palm, K. M., \& Rasmussen, M. L. (2004). Acceptance, mindfulness, and trauma. En S. C. Hayes, V. M. Follete y M. M. Linehan, Mindfulness and acceptance. Expanding the cognitive-behavioral tradition (pp. 192-208). New York: Guilford Press.

Gaudiano, B. A. (2011). Evaluating acceptance and commitment therapy: An analysis of a recent critique. International Journal of Behavioral Consultation and Therapy, 7, 54-65. Grumet, R., \& Fitzpatrick, M. (2016). A case for integrating values clarification work into cognitive behavioral therapy for social anxiety disorder. Journal of Psychotherapy Integration, 26, 11-21.

Hayes, S. C., Strosahl, K. D., \& Wilson, K. G. (1999). Acceptance and commitment therapy. An experiential approach to behavior change. New York: Guilford Press.

Hayes, S. C., Strosahl, K. D., \& Wilson, K. G. (2015). Terapia de aceptación y compromiso. Proceso y práctica del cambio consciente. (Mindfulness) (2.a ed.) (Trad. R. Álvarez). Bilbao: Desclée de Brouwer. (Original de 2012).

Hayes, S. C., Wilson, K. G., Gifford, E. V., Follette, V. M., \& Strosahl, K. (1996). Experiential avoidance and behavioral disorders: A functional dimensional approach to diagnosis and treatment. Journal of Consulting and Clinical Psychology, 64, 1152-1168.

Hayes, S. C., \& Smith, S. (2005). Get out of your mind and into your life. Oakland, USA: New Harbinger Publications.

Haynes, S. N., Godoy, A., \& Gavino, A. (2011). Cómo elegir el mejor tratamiento psicológico. Madrid: Pirámide.

Herman, J. (2004). Trauma y recuperación. Cómo superar las consecuencias de la violencia. Barcelona: Espasa.

Hervás, G., \& Jódar, R. (2008). Adaptación al castellano de la escala de dificultades en la regulación emocional. Clínica y Salud, 19, 139-156.

Higuera, J. G. (2006). La terapia de aceptación y compromiso (ACT) como desarrollo de la terapia cognitivo conductual. EduPsykhé: Revista de Psicología y Psicopedagogía, 5, 287-304.

Hofmann, S. G. (2008). Acceptance and commitment therapy: New wave or morita therapy? Clinical Psychology: Science and Practice, 15, 280-285.

Jaycox, L. H., Foa, E. B., \& Morral, A. R. (1998). Influence of emotional engagement and habituation on exposure therapy for PTSD. Journal of Consulting and Clinical Psychology, 66, 185-192.

Joseph, J. S., \& Gray, M. J. (2008). Exposure therapy for posttraumatic stress disorder. The Journal of Behavior Analysis of Offender and Victim Treatment and Prevention, 1, 6979.

Kanter, J. W., Mulick, P. S., Busch, A. M., Berlin, K. S., \& Martell, C. R. (2007). The behavioral activation for depression scale (BADS): Psychometric properties and factor structure. Journal of Psychopathology and Behavioral Assessment, 29, 191-202.

Kashdan, T. B., \& Rottenberg, J. (2010). Psychological flexibility as a fundamental aspect of health. Clinical Psychology Review, 30, 865878.

Kessler, R. C., Sonnega, A., Bromet, E., Hughes, M., \& Nelson, C. B. (1995). Posttraumatic stress disorder in the national comorbidity survey. Archives of General Psychiatry, 52, 1048-1060.

Labrador, F. J. (Coord.) (2008). Técnicas de modificación de conducta. Madrid: Pirámide.

León, O. G., \& Montero, I. (2003). Métodos de investigación en psicología y educación (3.a ed.). Madrid: Mc Graw Hill.

Linehan, M. M. (1993). Skills training manual for treating borderline personality disorder. New York: Guilford Press.

Luciano, C., Gutiérrez, O., \& Rodríguez, M. (2005). Análisis de los contextos verbales en el trastorno de evitación experiencial y en la terapia de aceptación y compromiso. Revista Latinoamericana de Psicología, 37, 333-358.

Martell, C. R., Dimidjian, S., \& Herman-Dunn, R. (2013). Activación conductual para la de- 
presión. Una guía clínica (Trad. J. A. Medina). Bilbao: Desclée de Brouwer. (Original de 2010).

McLean, C. P., \& Foa, E. B. (2011). Prolonged exposure therapy for post-traumatic stress disorder: A review of evidence and dissemination. Expert Review of Neurotherapeutics, $11,1151-1163$.

Mowrer, O. H. (1960). Learning theory and behavior. New York: Wiley.

Mueser, K. T., Gottlieb, J. D., Xie, H., Lu, W., Yanos, P. T., Rosenberg, S. D.,... McHugo, G. J. (2015). Evaluation of cognitive restructuring for post-traumatic stress disorder in people with severe mental illness. The British Journal of Psychiatry, 206, 501-508.

Mulick, P. S., Landes, S. J., \& Kanter, J. W. (2011). Contextual behavior therapies in the treatment of PTSD: A review. International Journal of Behavioral Consultation and Therapy, 7, 23-31.

Mulick, P. S., \& Naugle, A. E. (2010). Behavioral activation in the treatment of comorbid posttraumatic stress disorder and major depressive disorder. International Journal of Behavioral Consultation and Therapy, 5, 330-350.

Orengo, F., Rodríguez, M., Lahera, G., \& Ramírez, G. (2001). Prevalencia y tipos de trastorno de estrés postraumático en población general y psiquiátrica. Psiquis, 22, 169-176.

Orsillo, S. M., Roemer, L., Lerner, J. B., \& Tull, M. T. (2004). Acceptance, mindfulness, and cognitive-behavioral therapy. Comparisons, contrasts, and application to anxiety. En S. C. Hayes, V. M. Follete y M. M. Linehan, Mindfulness and acceptance. Expanding the cognitive-behavioral tradition (pp. 66-95). New York: Guilford Press.

Orsillo, S. M., Roemer, L., \& Barlow, D. H. (2003). Integrating acceptance and mindfulness into existing cognitive-behavioral treatment for GAD: A case study. Cognitive and Behavioral Practice, 10, 222-230.

Orsillo, S. M., \& Batten, S. V. (2005). Acceptance and commitment therapy in the treatment of posttraumatic stress disorder. Behavior Modification, 29, 95-129.

Páez-Blarrina, M., Gutiérrez-Martínez, O., Val-
divia-Salas, S., \& Luciano-Soriano, C. (2006). Terapia de aceptación y compromiso (ACT) y la importancia de los valores personales en el contexto de la terapia psicológica. International Journal of Psychology and Psychological Therapy, 6, 1-20.

Pereda, N. (2010). Consecuencias psicológicas a largo plazo del abuso sexual infantil. Papeles del Psicólogo, 31(2), 191-201.

Pereda, N., Gallardo-Pujol, D., \& Jiménez, R. (2011). Trastornos de personalidad en víctimas de abuso sexual infantil. Actas Españolas de Psiquiatría, 39, 131-139.

Pérez-Álvarez, M. (2007). La activación conductual y la desmedicalización de la depresión. Papeles del Psicólogo, 28(2), 97-110.

Pérez-Álvarez, M. (2012). Third-generation therapies: Achievements and challenges. International Journal of Clinical and Health Psychology, 12, 291-310.

Pérez-Álvarez, M. (2014). Las terapias de tercera generación como terapias contextuales. Madrid: Síntesis.

Pérez, J., \& Borrás, C. (2003). Técnicas de exposición y autoexposición. Madrid: Síntesis.

Perrin, M., Vandeleur, C. L., Castelao, E., Rothen, S., Glaus, J., Vollenweider, P., \& Preisig, M. (2014). Determinants of the development of post-traumatic stress disorder, in the general population. Social Psychiatry and Psychiatric Epidemiology, 49, 447-457.

Resick, P. A., Monson, C. M., \& Chard, K. M. (2014). Cognitive processing therapy veteran/military version: Therapist's Manual. Washington, DC: Department of Veterans Affairs.

Resick, P. A., Nishith, P., Weaver, T. L., Astin, M. C., \& Feuer, C. A. (2002). A comparison of cognitive-processing therapy with prolonged exposure and a waiting condition for the treatment of chronic posttraumatic stress disorder in female rape victims. Journal of Consulting and Clinical Psychology, 70, 867879.

Resick, P. A., \& Schnicke, M. K. (1992). Cognitive processing therapy for sexual assault victims. Journal of Consulting and Clinical Psychology, 60, 748-756.

Rosenberg, M. (1973). La autoimagen del ado- 
lescente y la sociedad (Trad. M. Galiano). Buenos Aires: Paidós. (Original de 1973).

Rothbaum, B. O., Meadows, E. A., Resick, P., \& Foy, D. W. (2003). Terapia cognitivo-conductual. En E. B. Foa, T. M. Keane y M. J. Friedman, Tratamiento del estrés postraumático (Trad. J. Jiménez) (pp. 81-106). Barcelona: Ariel. (Original de 2000).

Ruiz, Ma. A., \& Villalobos, A. (1994). Habilidades terapéuticas. Madrid: Fundación Universidad-Empresa.

Sanz, J., García-Vera, M. P., Espinosa, R., Fortún, M., \& Vázquez, C. (2005). Adaptación española del inventario para la depresión de Beck-II (BDI-II): 3. Propiedades psicométricas en pacientes con trastornos psicológicos. Clínica y Salud, 16, 121-142.

Sanz, J., \& Vázquez, C. (1994). Algunas consideraciones adicionales sobre la versión española de la escala de actitudes disfuncionales (DAS) de Weissman y Beck. Análisis y Modificación de Conducta, 20, 669-673.

Sarasua, B., Zubizarreta, I., de Corral, P., \& Echeburúa, E. (2013). Tratamiento psicológico de mujeres adultas víctimas de abuso sexual en la infancia: Resultados a largo plazo. Anales de Psicología, 29, 29-37.

Sosa, C., \& Capafóns, J. (2010). Estrés postraumático. Madrid: Síntesis.

Spielberger, C. D., Gorsuch, R. L., \& Lushene, R. E. (2011). STAI cuestionario de ansiedad

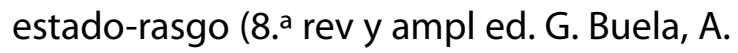
Guillén, \& N. Seisdedos). Madrid: TEA.

Twohig, M. P. (2009). Acceptance and commitment therapy for treatment-resistant posttraumatic stress disorder: A case study. Cognitive and Behavioral Practice, 16, 243252.

Valero, L., \& Ferro, R. (2015). Psicoterapia analítica funcional. El análisis funcional en la sesión clínica. Madrid: Síntesis.

Van Etten, M. L., \& Taylor, S. (1998). Comparative efficacy of treatments for post-traumatic stress disorder: A meta-analysis. Clinical Psychology and Psychotherapy, 5, 126-144.

Vázquez, A. J., Jiménez, R., \& Vázquez-Morejón, R. (2004). Escala de autoestima de Rosenberg: fiabilidad y validez en población clínica española. Apuntes de Psicología, 22,
247-255.

Wilson, K. G., Sandoz, E. K., Kitchens, J., \& Roberts, M. (2010). The valued living questionnaire: Defining and measuring valued action within a behavioral framework. The Psychological Record, 60, 249-272.

Wilson, K. G., \& Luciano, M. C. (2002). Terapia de aceptación y compromiso (ACT). Un tratamiento conductual orientado a valores. Madrid: Pirámide.

Wilson, K. G., \& Murrell, A. R. (2004). Values work in acceptance and commitment therapy. Setting a course for behavioral treatment. En S. C. Hayes, V. M. Follete y M. M. Linehan, Mindfulness and acceptance. Expanding the cognitive-behavioral tradition (pp. 120151). New York: Guilford Press.

Zayfert, C., \& Becker, C. B. (2008). Terapia cognitivo-conductual para el tratamiento del trastorno por estrés postraumático (Trad. L. D. Garibay). México: Manual Moderno. (Original de 2007). 
